\title{
Vibration Characteristics of Underground Structure and Surrounding Soil Underneath High Speed Railway Based on Field Vibration Tests
}

\author{
Biao Zhou, ${ }^{1,2}$ Fengshou Zhang $\mathbb{D}^{1,2}$ and Xiongyao Xie ${ }^{1,2}$ \\ ${ }^{1}$ Key Laboratory of Geotechnical \& Underground Engineering, Ministry of Education, Tongji University, Shanghai 200092, China \\ ${ }^{2}$ Department of Geotechnical Engineering, Tongji University, Shanghai 200092, China
}

Correspondence should be addressed to Fengshou Zhang; fengshou.zhang@tongji.edu.cn

Received 6 January 2018; Accepted 12 April 2018; Published 23 May 2018

Academic Editor: Sakdirat Kaewunruen

Copyright (C) 2018 Biao Zhou et al. This is an open access article distributed under the Creative Commons Attribution License, which permits unrestricted use, distribution, and reproduction in any medium, provided the original work is properly cited.

\begin{abstract}
A series of field vibration tests were carried out at an underground metro station underneath the high speed railway by installing accelerometers both on the side wall of the metro station and in the surrounding soil. Within the frequency domain of $0-200 \mathrm{~Hz}$, the attenuation, transmission, and frequency response properties of vibration for both the underground structure and the surrounding soil were analyzed and compared. The attenuation index is found to be decreased with the increase of underground structure stiffness. The existence of damping and coupling effect of the surrounding soil, as well as the interference of axle spectrum from excitation sources, makes it very challenging to separate the frequency response characteristics of structures from soil at FFT (Fast Fourier Transform) spectrum. The combined NExT (Natural Excitation Technique) and HHT (Hilbert-Huang Transform) method are thus used to study the waveforms and propagation velocities of vibration waves in underground structure and surrounding soil. The wave types and their speeds are determined and used for evaluating the structural elastic modulus. Compared with the attenuation index or natural frequency, wave velocity is easier to be recognized, is sensitive to the change of the structural stiffness, and requires limited number of sensors in the field. Based on the properties of the vibration characteristics studied in this work, the wave velocity based method is recommended for the health monitoring of underground structures.
\end{abstract}

\section{Introduction}

There has been great development of infrastructure constructions in China for the past three decades. The total length of the operating underground metro lines in China has been accumulating with an average speed of $270 \mathrm{~km}$ per year. As the serving time of these underground infrastructures gradually increases, the conditions of these systems may deteriorate rapidly due to the factors such as material aging, harsh environment, and dynamic loading. To ensure continuous safe operation of tunnels and other underground structures, the establishment of real-time health monitoring system for the evaluation of service performance is of great significance.

Health monitoring for the underground structures has been mainly relying on the static methods. For example, recent work by Bhalla et al. [1] and Bennett et al. [2] introduced the applications of environmental and static structural deformation monitoring system for the metro tunnels in London. Nevertheless, it was found that the structural damage in hidden places is difficult to be detected by using static methods. Meanwhile, static monitoring is only able to cover relatively small measurement area. Therefore, there is a great demand of developing vibration based health monitoring methods that have the potential of inspecting the overall underground structure as well as the surrounding soil.

Since 1970s, vibration based health monitoring system has been widely used for the real-time monitoring of structural properties for infrastructures above the ground [5-8]. The vibration characteristics of structures, determined by either from the properties of wave propagation within the structures or from the vibration modes, are the key to apply the vibration based health monitoring methods. Wave propagation properties mainly depend on their attenuation properties and waveform characteristics [9-11]. Vibration modes and 


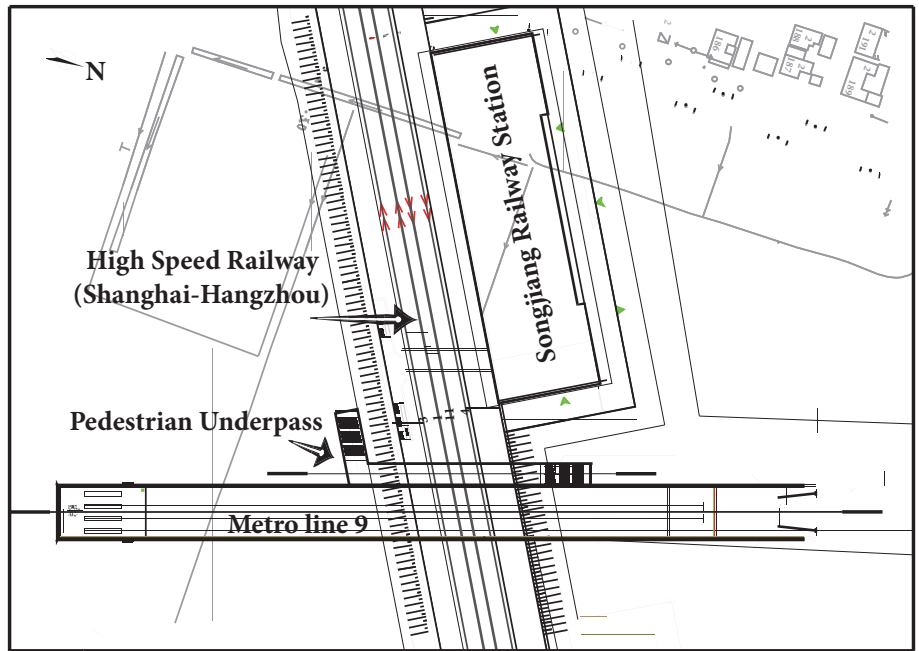

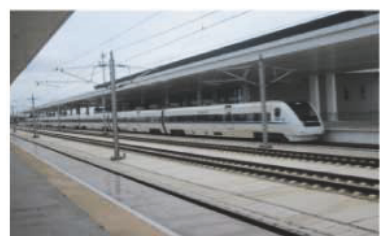

High Speed Railway

(Shanghai-Hangzhou)

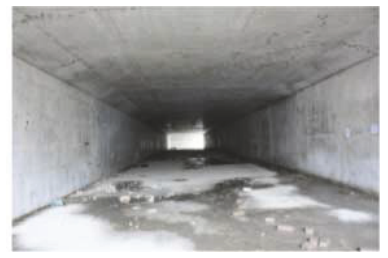

Pedestrian Underpass

(under construction)

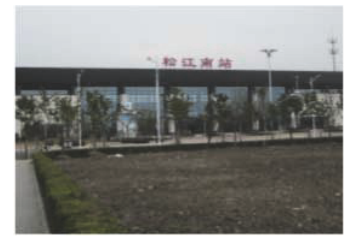

Songjiang Railway Station

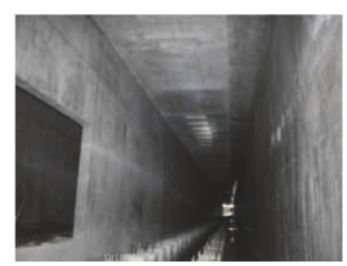

Metro line 9

(under construction)

FIGURE 1: Floor plan of the test site showing the intersection of Shanghai-Hangzhou high speed railway on the ground surface and the underneath Shanghai no. 9 metro line.

related methods are more commonly used, including natural frequency and frequency response function spectrum (FRFs) based methods [12-15], mode shape based methods [16], mode shape curvature/strain mode shape based methods $[17,18]$, model and related matrix based methods [19], and data driven methods [20]. Some signal processing techniques are proposed for the extraction of vibration characteristics [21]. In addition, there is some reported work which focused on the interaction between soil and structure in conjunction with the low-frequency seismic response [16]. However, the vibration characteristics of underground structures have not been well understood yet, which greatly limits the application of vibration based health monitoring methods in monitoring underground structures.

It has been well known that since the underground structures are strongly coupled with the surrounding soil, the constraining and damping effects as well as the dynamic behaviors of surrounding soil all cause major challenges for the recognition of vibration characteristics $[22,23]$, especially when applying those vibration modes based methods. Similarly, the mode characteristics of hydraulic structures and tall buildings are greatly affected by the coupling with the surrounding water and the connected foundation, respectively, and are typically polluted with noises $[24,25]$. Health monitoring of underground pipelines is therefore mostly based on wave propagation characteristics and related methods [26-28]. For tunnels, underground metro stations, and other large underground structures, the influence from the surrounding soil is more significant because of the large size and buried depth. Previous research on the vibration characteristics of underground structures mainly focused on the generating mechanism of vibration and the attenuation characteristics of vibration waves. For example, Heckl et al. [29], Yang and Hung [30], and Forrest and Hunt [31] presented the generating mechanisms of structure-borne vibrations caused by underground railway. Degrande et al. [32] reported the results of in situ vibration measurements at a site of London metro line and found that the vibration level and the frequency content is a function of train speed and the distance to the tunnel. The above research however was not able to systematically study the vibration characteristics of large underground structures and compare them with the vibration characteristics of the surrounding soil.

In this work, in order to investigate the vibration characteristics of underground structures and discuss the feasibility of using vibration based methods for the health monitoring of large underground structures, a series of field vibration tests were carried out at an underground metro station underneath the high speed railway. Within the frequency domain of $0-200 \mathrm{~Hz}$, the attenuation, transmission, and frequency response properties of vibration for both the underground structure and the surrounding soil were analyzed and compared. Based on the properties of the vibration characteristics, some suggestions were given for the health monitoring of underground structures by using vibration based methods.

\section{Engineering Background and Field Test Plan}

2.1. Engineering Background. As shown in Figure 1, the test site is located at the underground metro station of Shanghai no. 9 metro line. The metro line is nearly perpendicularly intersected by the operating Shanghai-Hangzhou high speed railway on the ground surface. The high speed railway operates with a train speed of either $180 \mathrm{~km} / \mathrm{h}$ with train type $\mathrm{CRH} 2 \mathrm{a}$ or $300 \mathrm{~km} / \mathrm{h}$ with train type CRH380a. The metro station was under construction when the field vibration tests were carried out. Figure 2 shows the cross section view of the metro station with high speed railway on the ground surface. The details of the soil layers along the depth and the corresponding shear wave velocity are shown on the right side of the plot. The distance from the roof of the metro station to the high speed railway is about $4.55 \mathrm{~m}$. The metro station 


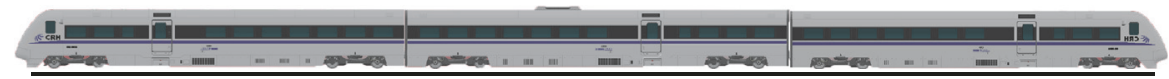

Railway Subgrade

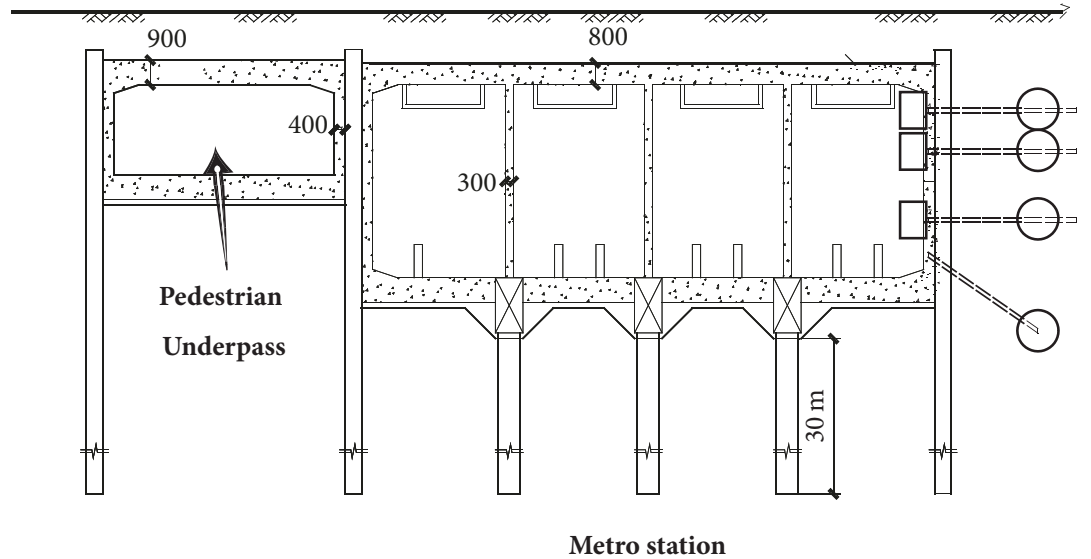

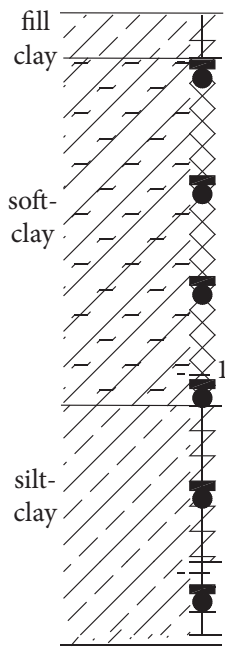

soil layer

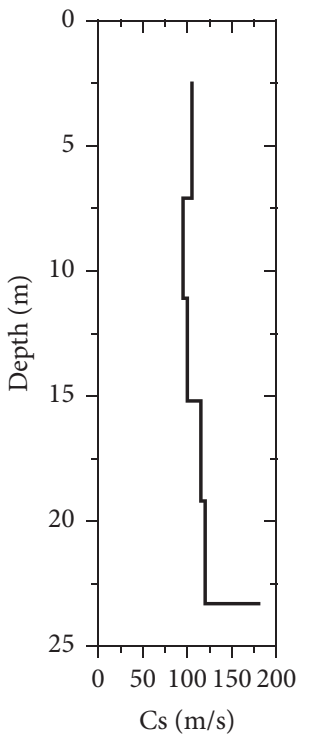

Measurement point

Figure 2: Cross section view of the metro station with high speed railway on the ground surface; soil layers along the depth and the corresponding shear wave velocity are listed on the right.
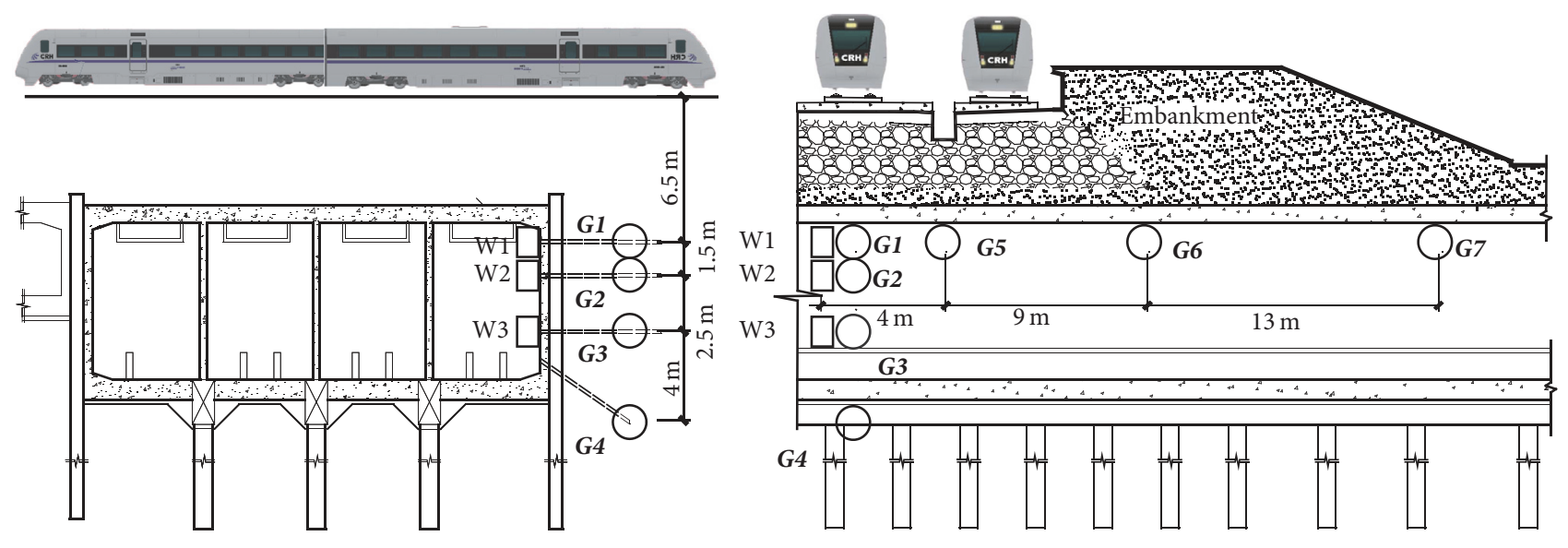

G1-G7: Measurement points in the soil

W1-W3: Measurement points on the side wall of metro station

FIGURE 3: Design of measurement arrays.

was excavated mainly in the soft clay and silt clay layers. The results of SPT (Standard Penetration Test) [33] showed that the shear wave velocity in these soils is about $110 \mathrm{~m} / \mathrm{s}$ and the compression wave velocity is about $687 \mathrm{~m} / \mathrm{s}$ [34].

2.2. Design of Measurement Arrays. In order to study the wave propagation in both the underground metro station and the surrounding soil and identify the difference of wave propagation characteristics in these two mediums, three measurement arrays were installed in the field, as shown in Figure 3. The first array with three measurement points (W1 to W3) was vertically aligned on the side wall of the metro station. The second array with four measurement points (G1 to G4) was parallel to the first array but buried into the soil surrounding the metro station. The third array with three measurement points (G5 to G7) was at the same elevation of G1 but along the horizontal direction and parallel with the side wall of the metro station. The second and 
TABLE 1: Parameters of accelerometer.

\begin{tabular}{lcccc}
\hline Item & Sensitivity $(\mathrm{V} / \mathrm{g})$ & Max acceleration $(\mathrm{g})$ & Frequency range $(\mathrm{Hz})$ & Resolution $(\mathrm{g})$ \\
\hline Value & 40 & 1.2 & $0.1-300$ & $2 \times 10^{-6}$ \\
\hline
\end{tabular}

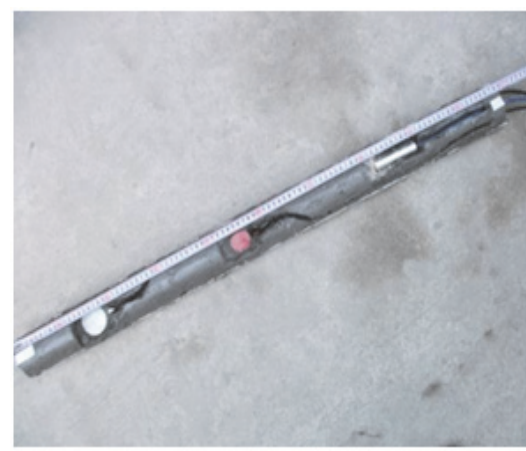

1. Prefabricate soil column with accelerometers embedded

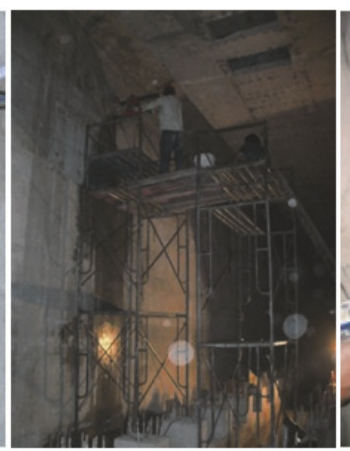

2. Drill the hole for the installation of soil column

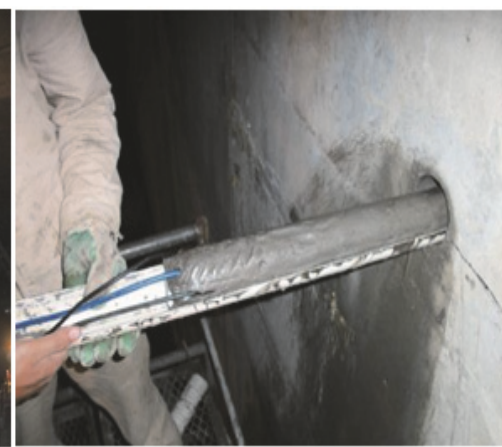

3. Install the soil column

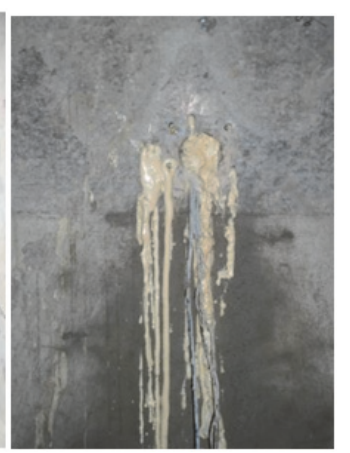

4. Backfill and seal the drilling hole

FIgURE 4: Procedure for the installation of accelerometers in the soil.

third arrays were used to test the vertical and horizontal wave propagation in the soil, respectively. The LC130 IC piezoelectric accelerometer was employed in the field test. The specific parameters of the accelerometer are listed in Table 1.

2.3. Installation Procedure of Accelerometers. The installation procedure of accelerometers W1 to W3 followed the standard of ISO 5348 [35]. Accelerometers G1 to G7 were located inside the soil which is behind the wall of the metro station and also underneath the high speed railway. The installation was through a drilling hole from the wall of the metro station. As shown in Figure 4, the installation procedure for accelerometers in the soil has the following steps.

(1) Prefabricate soil column with accelerometers embedded: a soil column with diameter of $8 \mathrm{~cm}$ and length of $1 \mathrm{~m}$ was made from clay. Accelerometers along with some earth pressure sensors and water pressure sensors were embedded in the soil.

(2) Drill the hole for the installation of soil column: a hole with diameter of $8.9 \mathrm{~cm}$ and length of $3 \mathrm{~m}$ was drilled starting from the wall of the metro station. The drilling points were determined by a laser positioning system.

(3) Install the soil column: after the hole was drilled, the soil column placed in a PVC pipe was inserted into the drilling hole.

(4) Backfill and seal the drilling hole: after the soil column was placed in the drilling hole, the part of the hole in the soil was infilled with clay while the part of the hole on the wall was infilled with quick-setting cement first and then sealed with waterproof polyurethane.

\section{Attenuation Characteristics of Vibration}

Vibration attenuation index is one of the important parameters to determine the wave types and evaluate the attenuation characteristics [36]. In this section, based on the data gathered by accelerometers installed both on the side wall of the metro station and in the surrounding soil, we analyze the attenuation indices in both the horizontal and vertical directions and investigate the types of the vibration waves and the association between the attenuation characteristics and the train speed as well as the structural stiffness.

3.1. Vibration Attenuation Characteristics in the Half Space Medium. In the half space medium, the vibration waves caused by pulse loads propagate outward as a combination of Rayleigh wave, compression wave, and shear wave. The propagation of elastic waves is also accompanied by the wave attenuation which includes two parts, one is the decay of the amplitude due to the increasing distance from the source and the other is due to the material damping and energy dissipation. The attenuation of vibration waves can be described by the following equation [37]:

$$
v=v_{0} \cdot\left(\frac{r}{r_{0}}\right)^{-m} \cdot e^{-\alpha\left(r-r_{0}\right)}
$$

while $v$ and $v_{0}$ are the vibration magnitude at the measurement point and the vibration source, respectively; $r_{0}$ is the measured distance from the vibration source to a reference point; $r$ is the distance between the measurement point and the vibration source; $\alpha$ is the material damping ratio; $m$ is the size related attenuation index. Equation (1) suggests that $m$ is the slope of the vibration magnitude versus the measured distance, both in logarithmic scales.

Table 2 lists some specific values of $m$ for different physical sources from the literature. It shows that the vibration wave propagation and attenuation depend on the types of vibration source and the wave types. The $m$ value for the train with short length and high speed $(m=1.5)$ is different from the train with long length and slow speed $(m=1.0)$ [4]. 
TABLE 2: Selection of attenuation index $m$ for different physical sources from the literature.

\begin{tabular}{lccc}
\hline Physical sources & Type of source & Wave type & Attenuation index $m$ \\
\hline Line source [3] & Line & Rayleigh & 0 \\
& & Body & 0.5 \\
Point source [3] & Point & Rayleigh & 0.5 \\
Short length and high speed train [4] & Body & 1.0 \\
Long length and slow speed train [4] & Line & Body & 1.5 \\
\hline
\end{tabular}

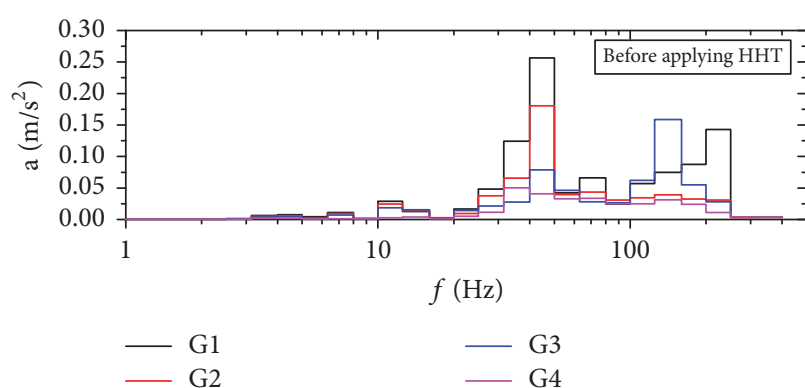

(a)

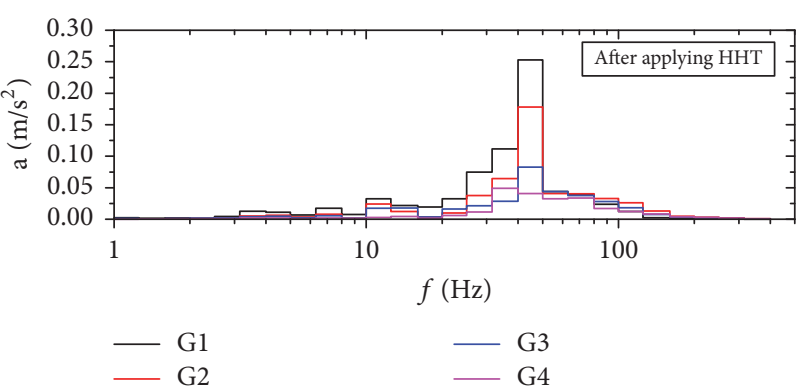

(b)

FIGURE 5: One-third octave frequency bands of measurement points G1 to G4 before (a) and after (b) applying HHT.

3.2. Evaluation of Vibration Level and Determination of Attenuation Index. Indicators which can be used to evaluate the vibration level include peak particle velocity (PPV), root mean square (RMS), continuous RMS, vibration magnitude, and vibration peak factor. In this work, the PPV value is used for the evaluation of attenuation characteristics. The detailed procedures are listed as follows.

(1) Denoising Based on HHT (Hilbert-Huang Transform). Based on the original frequency spectrum of acceleration from each measurement point, it can be seen that the frequency of the train vibration wave falls into the range of $2 \mathrm{~Hz}$ to $100 \mathrm{~Hz}$. In order to ensure consistency on the frequency spectrum for all measurement points, HHT transform [38] was applied to filter out the signal with frequency greater than $100 \mathrm{~Hz}$. HHT method was pioneered by Huang et al. [38] for nonlinear and nonstationary signal analysis. Figure 5 shows the one-third octave frequency bands of measurement points G1 to G4 before (a) and after (b) applying HHT. After the HHT processing, the frequency spectrum in the range of 0 to $100 \mathrm{~Hz}$ is highly consistent among all measurement points, and the difference between G1 and G3 in the $100 \mathrm{~Hz}$ to $300 \mathrm{~Hz}$ range is mostly suppressed.

(2) Determine the Attenuation Index. As shown in Figure 6, the time history of the velocity is obtained by integrating acceleration. Take logarithm on both sides of (1) and reference value of $5 e^{-8} \mathrm{~m} / \mathrm{s}$ is used to convert the velocity on the left side to $\mathrm{dB}$; (1) becomes

$$
\begin{aligned}
20 \times \lg \frac{v / 5 e^{-8}}{v_{0} / 5 e^{-8}}(\mathrm{~dB})= & -20 \times m \lg \frac{r}{r_{0}}-20 \times \lg e \\
& \times \alpha\left(r-r_{0}\right) .
\end{aligned}
$$

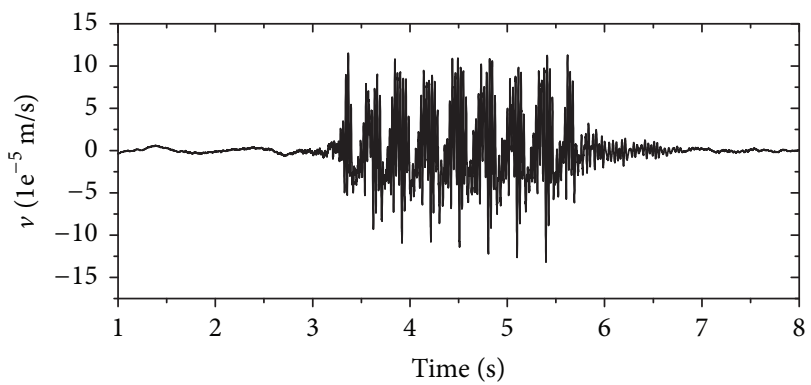

FIGURE 6: The velocity time history of G1 by integrating acceleration.

According to the procedure described above, the maximum $\mathrm{dB}$ value of velocity was obtained at each of the measurement point. And the attenuation index along both the horizontal and vertical directions can be determined. The details can be seen in Section 3.4.

3.3. Automatic Determination of the Train Speed and Train Length Based on Autocorrelation Function. The attenuation of vibration induced by a moving train is closely related to the speed of the train. Therefore, we proposed a method by which the speed of the train can be automatically determined by using the autocorrelation function.

When a train passes by with uniform speed, the wheelrail force and its response function is a periodic function of the passing time of one carriage. Therefore the time history of autocorrelation function reaches the peak at the interval of the passing time of one carriage. Figure 7 shows the time history of autocorrelation function for the acceleration response of a CRH380a train. There are a total of nine peaks in the autocorrelation function with the time interval of $0.296 \mathrm{~s}$ 


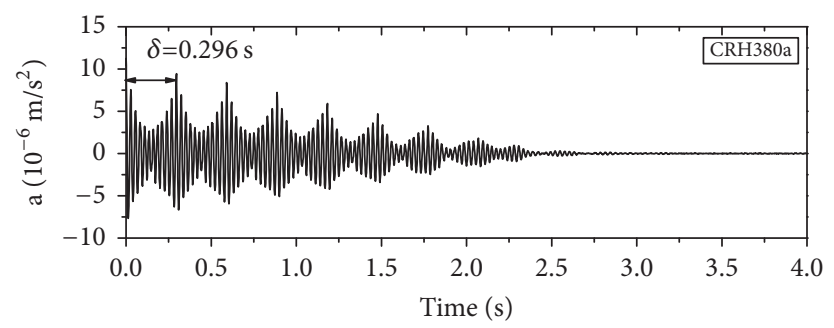

Figure 7: The time history of autocorrelation function for the acceleration response of train vibration.

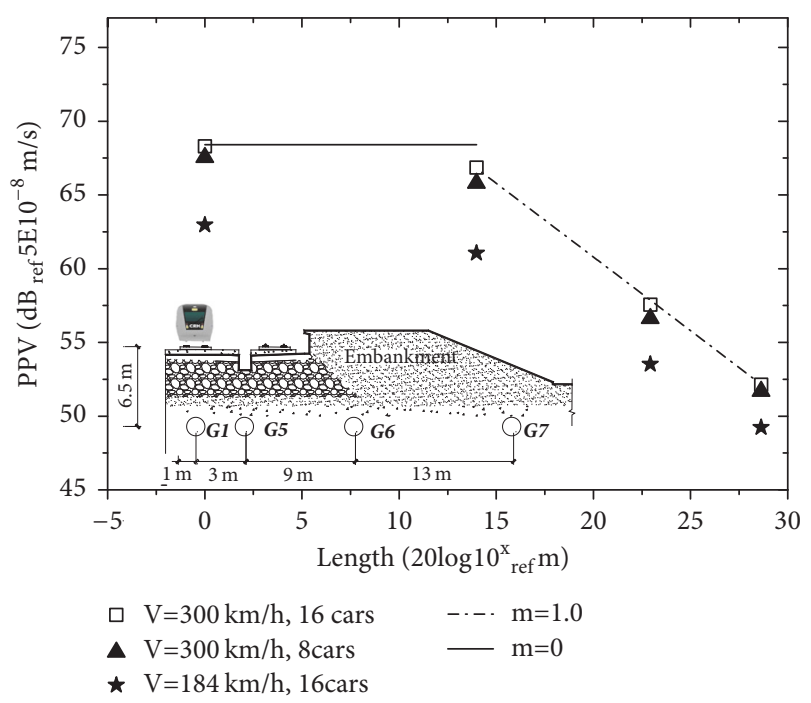

FIGURE 8: Horizontal attenuation of vibration waves in the soil for two different train velocities and train lengths.

which indicates that the passing time $\delta_{t}$ of each carriage is $0.296 \mathrm{~s}$. Since the length of one carriage $L$ is $25 \mathrm{~m}$, the running speed of the train can be calculated as $v=L / \delta t=25 / 0.296=$ $84.45 \mathrm{~m} / \mathrm{s}=304 \mathrm{~km} / \mathrm{h}$. The calculated train speed fit well with the designed operating speed $300 \mathrm{~km} / \mathrm{h}$.

At the same time, eight peaks can be identified from Figure 7, which indicates that there are a total of eight car carriages. Thus the train length can be further obtained based on the number of carriages with the given carriage length.

\subsection{Vibration Attenuation Characteristics in the Metro Station and Surrounding Soil}

(1) Characteristics of Horizontal Attenuation. Figure 8 plots the horizontal attenuation of vibration in the soil for the two different train velocities and car lengths. All curves show the pattern of two linear pieces. The slope of the curve between G1 to G5 is nearly zero $(m=0)$ while the slope between G5 and G7 is close to $1(m=1)$. The vibration magnitude for the case with velocity of $300 \mathrm{~km} / \mathrm{h}$ and 16 carriages is $1 \mathrm{~dB}$ larger than the case with the same velocity but 8 carriages and $5 \mathrm{~dB}$ larger than the case with the same train length but velocity of $184 \mathrm{~km} / \mathrm{h}$.

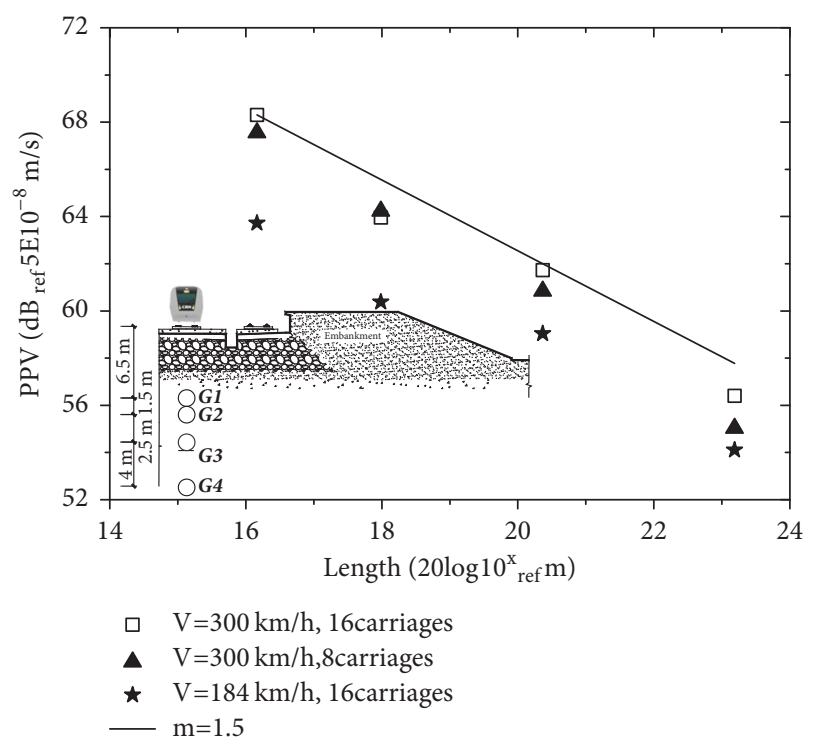

FIGURE 9: Vertical attenuation of vibration waves in the soil for two different train velocities and train lengths.

The results in Figure 8 clearly indicate the difference of horizontal attenuation of vibration waves below the track and away from the track. The zero attenuation index below the track indicates that horizontal attenuation is limited. The attenuation index $m$ away from the track is 1 , consistent with the value of long length and slow speed train as shown in Table 2 and different from the value of short length and high speed train $(m=1.5)$.

(2) Characteristics of Vertical Attenuation. Similarly, the vertical attenuation of vibration waves in the surrounding soil for the two different train velocities is plotted in Figure 9. Different from the horizontal attenuation, the three curves in Figure 9 show only one slope. The attenuation index $m$ is 1.5 for the all the cases listed. These two index values are consistent with the values for the case of short length and high speed train as shown in Table 2.

Figure 10 plots the vertical attenuation of vibration waves in the underground structure for two different train velocities and train lengths. Although the vibration level in the structure is smaller than the one in the soil, similar attenuation characteristics are obtained. The attenuation index $m$ is between 0.5 and 1 for all the three cases listed.

In summary, the calculated attenuation index $m$ for the propagation of vibration waves in the underground structure and surrounding soil is listed in Table 3.

By comparing Tables 2 and 3, the results indicate that the body waves including shear wave and compression wave are the main vibration wave modes in both the underground structure and surrounding soil. However, the attenuation characteristics of body waves are affected by the stiffness of the underground structure and can be different from the one in the half space medium. The effect of structural stiffness is more profound in the horizontal direction and resulting in the decrease of the attenuation index $m$ from 1.5 to 1 . 
TABLE 3: Calculated attenuation index $m$ for the propagation of vibration waves in the underground structure and soil.

\begin{tabular}{lccc}
\hline Physical sources & Velocity $(\mathrm{km} / \mathrm{h}) /$ number of carriages & Horizontal direction & Vertical direction \\
\hline \multirow{3}{*}{ Soil surround the metro station } & $180 / 16$ & 1 & 1.5 \\
& $300 / 16$ & 1 & 1.5 \\
\hline \multirow{2}{*}{ Metro station } & $300 / 8$ & $/$ & 1.5 \\
& $180 / 16$ & $/$ & 0.8 \\
\hline
\end{tabular}

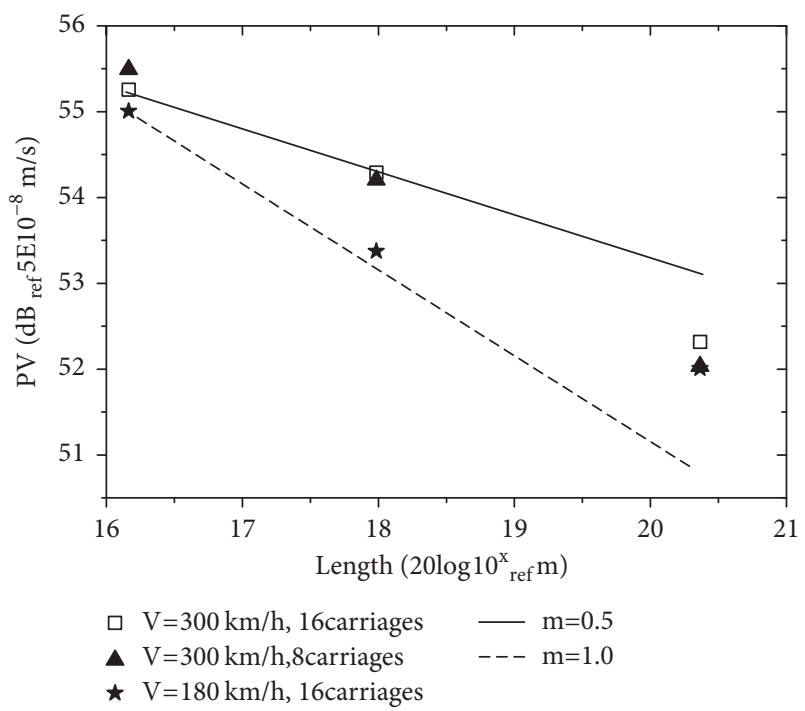

FIGURE 10: Vertical attenuation of vibration waves in the underground structure for two different train velocities and train lengths.

But the propagation of body waves in the vertical direction is less affected by the stiffness of the metro station, and the attenuation index is consistent with the one for the half space medium. Meanwhile, the influence of train length (i.e., carriage numbers) is also considered, and it is found that the increase of carriages from 8 to 16 will lead to the increase of vibration magnitude but has limited impact to the attenuation index $m$. Therefore, the attenuation index can be used to determine the types of the vibration wave but can hardly be used to precisely evaluate the performance of underground structures.

\section{Characteristics of Frequency Response Spectrum and Interference from the Vibration Source}

The natural frequency and frequency response function spectrum (FRFs) based methods are common methods in structure health monitoring, but susceptible to temperature and the characteristics of vibration source [12-15]. In order to analyze the frequency response of the underground structure and the surrounding soil and explore the interference from the vibration source, three different cases corresponding for the effects of a moving train with uniform speed, a stopping train, and ambient vibration, were investigated.

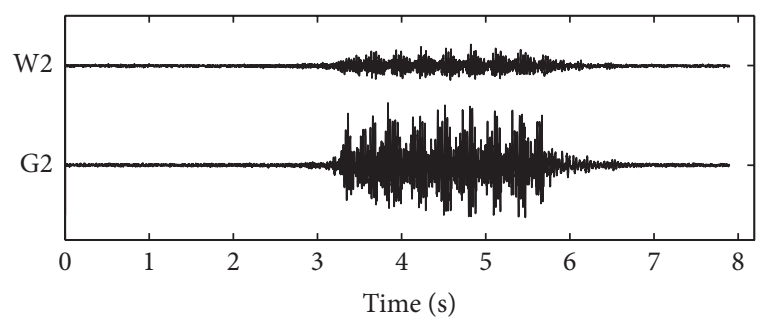

FIGURE 11: The time history of the acceleration for the measurement points W2 on the wall of the metro station and G2 in the soil when a CRH380a train is passing by with uniform speed.

4.1. Characteristics of Frequency Spectrum for a Moving Train with Uniform Speed. Figure 11 shows the time history of the acceleration for the measurement points W2 on the wall of the metro station and G2 in the soil when a CRH380a train is passing by with uniform speed of $300 \mathrm{~km} / \mathrm{h}$. Although the two measurement points were at the same depth, the acceleration response for the measurement point in the soil is much larger than the one on the wall of the metro station.

Figures 12(a) and 12(b) show the FFT (Fast Fourier Transform) spectrum of measurement points W2 and G2, respectively, in contrast with the axle spectrum of the moving train in Figure 12(c). Axle spectrum is generated by the periodic train wheel load of a moving train with uniform speed. It can be expressed by the equation below:

$$
u(t)=\sum_{i=1}^{n} u\left(t-T_{i}\right)
$$

while $T_{i}$ is the time lag of the train wheel and $i$ is the number of the train wheels. Equation (3) can be further expressed as follows:

$$
\widetilde{U}(f)=U_{0}(f) \sum_{i=1}^{n} e^{i 2 \pi f T_{i}}=U_{0}(f) X(f)
$$

while $U_{0}(f)$ is the uniaxial displacement response amplitude and $X(f)$ characterizes the spatial distribution function of the wheels.

Substitute the following values into (4): train speed $304 \mathrm{~km} / \mathrm{h}$ based on the calculation in Section 2, length of single carriage $25 \mathrm{~m}$, wheelbase $2.5 \mathrm{~m}$, and length between bogie pivot centers $18 \mathrm{~m}$. The axle spectrum then can be obtained as shown in Figure 12(c). It can be found that the peaks on the FFT spectrum of W2 and G2 agree well with those peaks on the axle spectrum which makes it hard to 


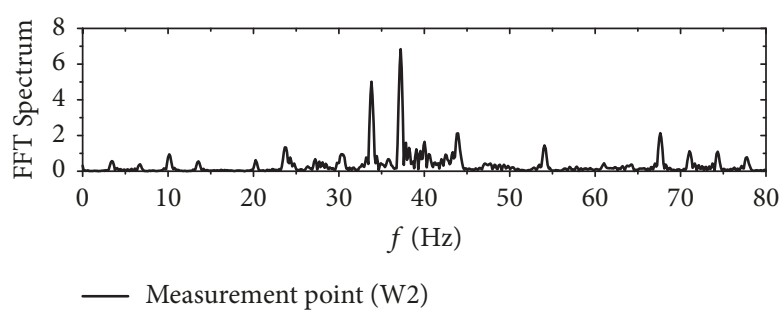

(a)

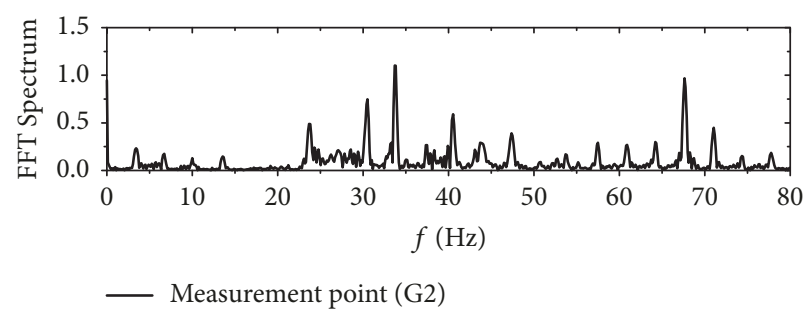

(b)

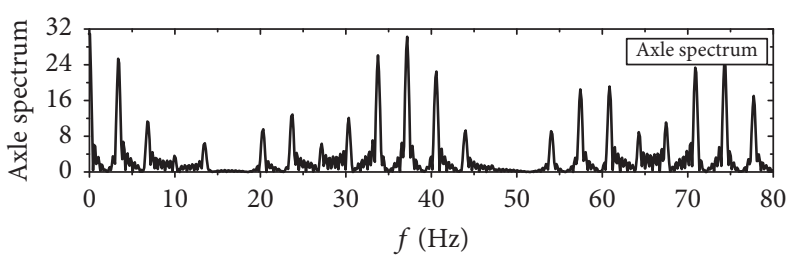

(c)

FIGURE 12: (a) FFT spectrum of measurement point W2, (b) FFT spectrum of measurement point G2, and (c) the axle spectrum of the moving train.

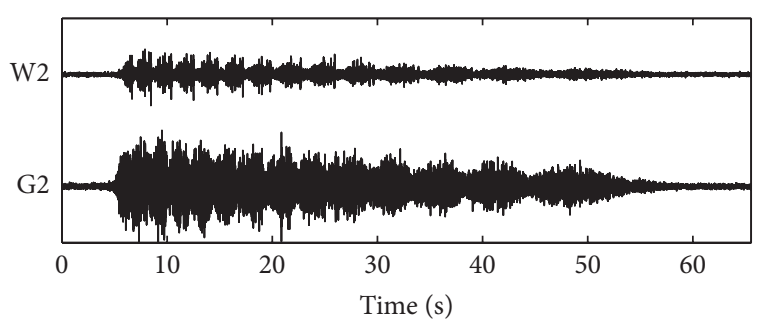

FIGURE 13: Time history of the acceleration for measurement points W2 on the wall of the metro station and G2 in the soil for a stopping train.

identify and differentiate the natural frequency spectrums for the train, rail, and the underground structures.

The results above show that the transient response generated by the moving train with uniform speed is dominated by the axle spectrum. Technically by the FFT method, it is difficult to recognize and extract the nature frequency for the vibration mode and the cut-off frequency for the propagation mode.

4.2. Characteristics of Frequency Spectrum for a Stopping Train. In order to avoid the interference from the axle spectrum, the characteristics of frequency spectrum for a stopping train was also analyzed. Figure 13 shows the time history of the acceleration for measurement points $\mathrm{W} 2$ on the wall of the metro station and G2 in the soil for a stopping train.

The power spectral density (PSD) of the two signals can be computed by applying the "pwelch" function in Matlab with the parameters of pwelch ( $x$, hanning(512),256, N, 1000), as shown in Figures 14(a) and 14(b). It can be seen that the response frequency for a stopping train mainly falls into the range of $20 \mathrm{~Hz}$ to $200 \mathrm{~Hz}$ and has wider distribution than the case when the train is moving with uniform speed.

$$
\begin{aligned}
H(f) & =\frac{P_{x y}}{P_{x x}} \\
& =\frac{\operatorname{cpsd}(x, y, \text { hanning }(512), 256, \mathrm{~N}, 1000)}{p w e l c h(x, \text { hanning }(512), 256, \mathrm{~N}, 1000)}
\end{aligned}
$$

while $x$ and $y$ are time history of the acceleration for W2 and $\mathrm{G} 2$, respectively.

Meanwhile, based on the "cpsd" and "pwelch" functions in Matlab, a transfer function can be defined in (6) to illustrate the vibration transmission properties between the soil and the structure. Figure 14(c) shows the curve of the transfer function. The value of the transfer function is nearly 1 within the range of $1 \mathrm{~Hz}$ to $10 \mathrm{~Hz}$ which indicates that the structure and soil have good transmission properties. Subsequently, the value of the transfer function gradually decreases from 1 which reveals the gradual enlargement of the difference of the vibration response between these two measurement points. 


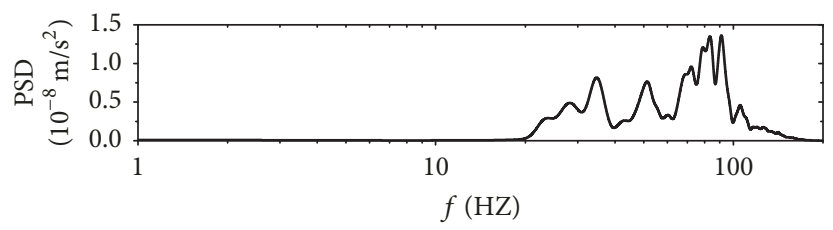

G2

(a)

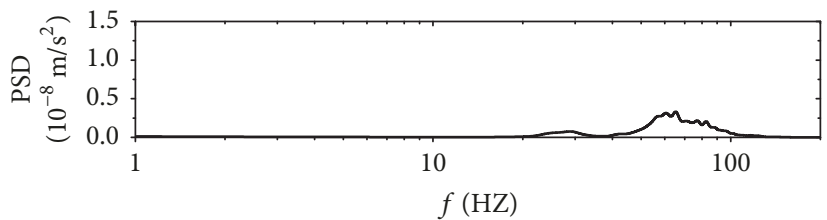

- W2

(b)

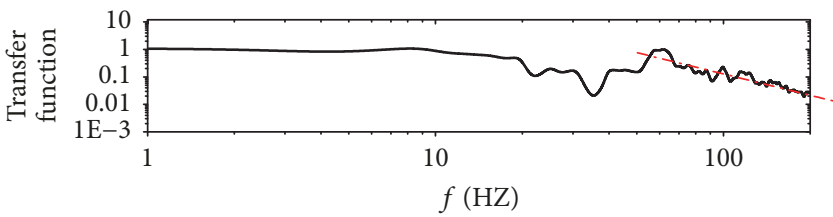

(c)

FIGURE 14: (a) PSD frequency spectrum of signals for measurement point W2, (b) PSD frequency spectrum of signals for measurement point $\mathrm{G} 2$, and (c) the transfer function of these two signals.

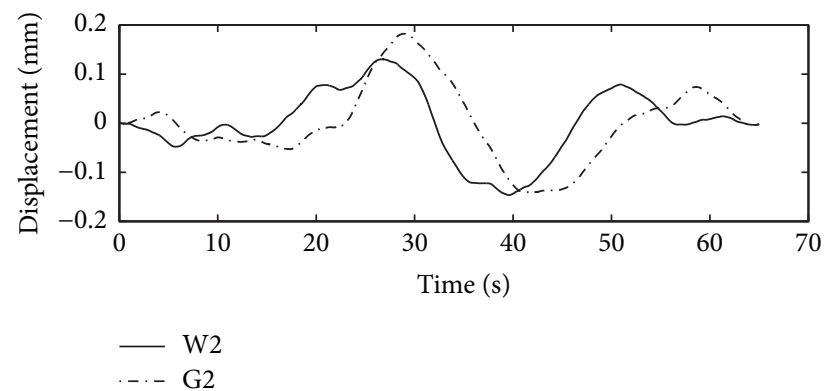

FIGURE 15: Recorded vertical displacement history for measurement points W2 and G2.

The transfer function stabilizes around 1 between 1 and $10 \mathrm{~Hz}$ which means that the vibration of metro station and surrounding soil are synchronous at low frequency. The vertical displacement history of the two measurement points W2 and G2 in Figure 15 further proves that the vertical displacements of these two points have the same magnitude level.

The difference between the one-third octave band spectra of the transfer functions between the measurement points in the soil and on metro station wall is also provided in Figure 16. Similar with PSD frequency spectrum, the value of the transfer function stabilizes around 1 between 1 and $10 \mathrm{~Hz}$. It is also found that the transfer function is considerably reduced between 10 and $100 \mathrm{~Hz}$. And some moderate amplifications are found in the low-frequency range around $20 \mathrm{~Hz}$ and

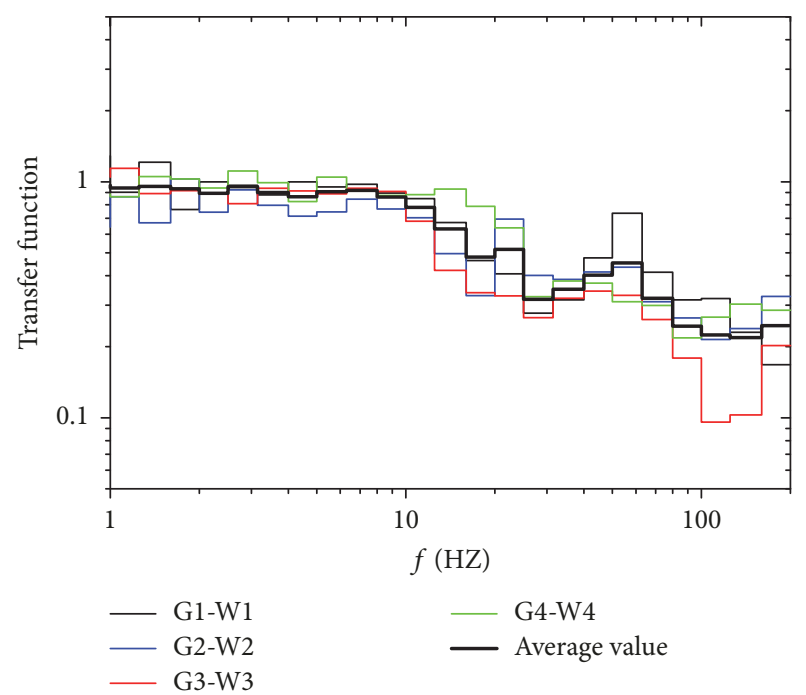

FIGURE 16: One-third octave band spectra of the transfer functions between the measurement points in the soil and on the metro station wall.

$50 \mathrm{~Hz}$, which is probably related to the resonance frequency of the structure and surrounding soil.

The above analysis of the frequency response for measurement points on the wall of the metro station and in the soil when the train was stopping shows that the frequency spectrum is dominated by the resonance frequency of the train and rail. Meanwhile, the structure and soil show good 


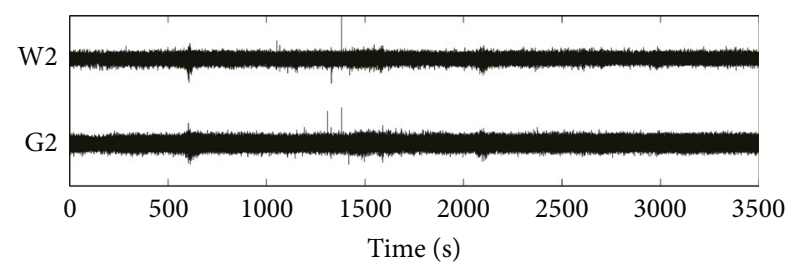

FIGURE 17: Time history of the acceleration for measurement points W2 on the wall of the metro station and G2 in the soil with natural excitation in the night.

transmission properties at the low frequency range below $10 \mathrm{~Hz}$; thus it is challenging to differentiate the performance change of the structure and soil based on the characteristics of frequency spectrum. In this respect, different from the applications for bridges and tall buildings, the structural health monitoring for the underground structures requires wider frequency band. Meanwhile, some resonance frequencies around $20 \mathrm{~Hz}$ and $50 \mathrm{~Hz}$ are found from the moderate amplification at the one-third octave band spectra of the transfer functions. However the accurate value need to be further investigated at the following section.

\subsection{Characteristics of Frequency Spectrum from Ambient} Vibration Analysis. In order to accurately determine the resonance frequency and avoid the interference due to train operation, the ambient vibration test was conducted in the night with the benefit that the surrounding area of the test station is farmland and there is limited vibration disturbance. The characteristics of frequency spectrum of structural natural vibration and propagation mode were analyzed.

The sampling frequency for the natural excitation was $1000 \mathrm{~Hz}$. Figure 17 shows the time history of the acceleration for measurement points W2 on the wall of the metro station and G2 in the soil with a total length of 4 hours. The data was further processed by NExT (Natural Excitation Technique) method [39]. NExT utilizes the auto or cross-correlation function of acceleration for measurement points under the condition of white noise excitation.

Figure 18(a) shows the autocorrelation function after the NExT processing for measurement point W2 and Figure 18(b) shows the corresponding PSD frequency spectrum from Figure 18(b); some peaks can be found at $21 \mathrm{~Hz}, 49.5 \mathrm{~Hz}$, $80.5 \mathrm{~Hz}$, and $122.5 \mathrm{~Hz}$. It can be concluded that various types of vibration wave modes are excited with natural excitation. But all the peaks in the PSD frequency spectrum are relatively flat due to the effect of soil damping.

Similarly, the same processing was done for the signal of G2. All the peaks identified in Figure 18(b) also appeared in Figure 19(b), which suggests that soil and structure have some shared vibration modes. In addition, Figure 19(b) shows some peaks at the frequencies of $61 \mathrm{~Hz}, 101.5 \mathrm{~Hz}$, and $142 \mathrm{~Hz}$, which implies that some of the vibration modes only exist in the soil but not in the underground structure.

In summary, from the analysis of transfer function, it is found that the structure and soil show good transmission properties at the low frequency range below $10 \mathrm{~Hz}$, but the difference of the vibration response considerably increases between 10 and $100 \mathrm{~Hz}$. Meanwhile, some resonance frequencies can be found around $21 \mathrm{~Hz}, 49.5 \mathrm{~Hz}, 80.5 \mathrm{~Hz}$, and $122.5 \mathrm{~Hz}$. However, in contrast to the applications for bridges and tall buildings, the accurate recognition and extraction of the frequency response characteristics for the structure becomes more challenging and need wider frequency band because of the constraining and damping effects as well as the dynamic behaviors of surrounding soil, together with the interference of axle spectral and other characteristics of the train and rail system.

\section{Waveforms and Propagation Velocities of Vibration Waves}

Waveforms and propagation velocities of vibration waves are important features which can be used to determine the wave types and back calculate the elastic modulus of the structures. Accordingly, the service performance of the structures can be evaluated by monitoring the changes of the wave velocities. In this section, the wave velocities between different measurement points were extracted by combining NExT and HHT. Vibration wave types and the propagation characteristic both in the structure of metro station and in the soil were then analyzed and compared.

\subsection{Waveforms and Propagation Velocities Determination by} Combining NExT and HHT Method. Velocities of the vibration waves are often obtained either through measuring the travel time between measurement points in the time domain or by determining the wave phase shift based on methods such as SASW in the frequency domain [40]. Obtaining the wave phase shift in the frequency domain requires that the acceleration sensors have stable performance and wide frequency range. As a result, achieving both economic and sustainable health monitoring system meets great challenges. Therefore, in this work we utilized the combined NExT and HHT method to extract different vibration waves from the signal and calculate the corresponding wave velocities. NExT is used to obtain the free oscillation signal from the random response; then the needed propagation modes are decomposed with HHT method. Because the accelerometers are only arranged at the vertical direction, an illustrated example of processing the wave velocity at measurement points G1 to G4 is given in the section below.

\subsection{Propagation Velocities of Vibration Waves in Soil}

(1) Propagation Velocities of Vibration Waves in the Vertical Direction. Figure 20(a) shows the time history of the acceleration for measurement points G1 to G4 after 5000-second continuous acquisition. The signal included the passing by of the train, the stopping of the train, and also the natural excitation. The signal was further processed with NExT with the superposition length of 128 data points. Figure 20 (b) plots the autocorrelation function after the NExT processing for G1 which indicates a periodic wave with attenuation in the time domain. The PSD frequency spectrum in Figure 20(c) shows 


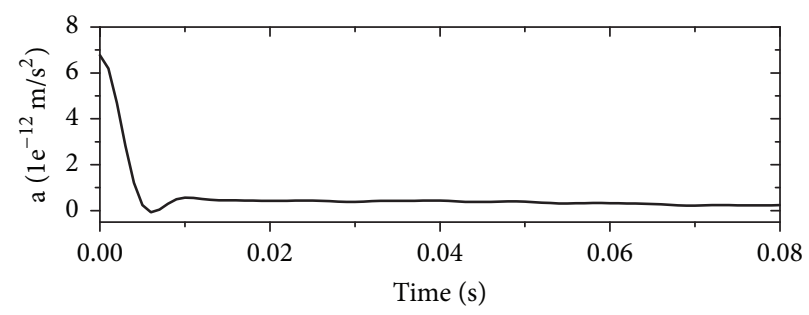

(a)

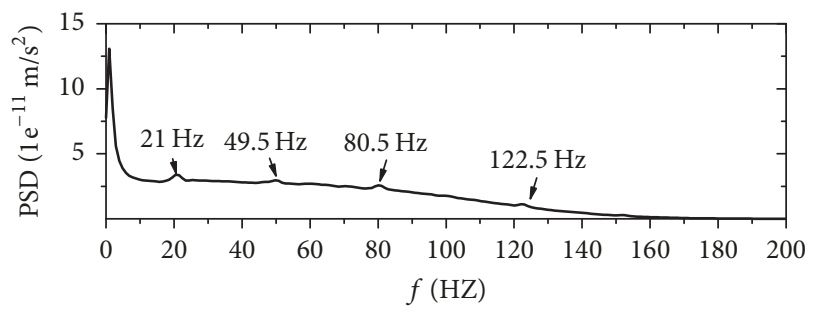

(b)

FIGURE 18: (a) Autocorrelation curve after the NExT processing and (b) its PSD frequency spectrum for measurement point W2 with natural excitation in the night.

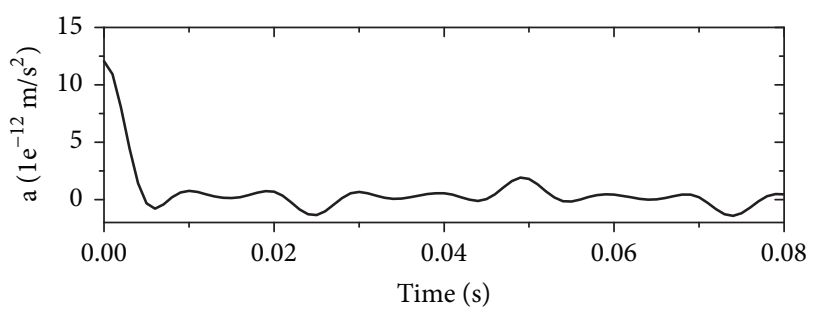

(a)

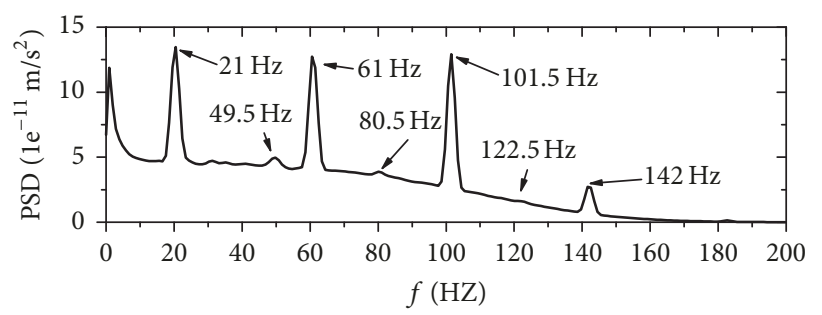

(b)

FIGURE 19: (a) Autocorrelation curve after the NExT processing and (b) its frequency spectrum for measurement point G2 with natural excitation in the night.

that the autocorrelation function is a free oscillation signal with the main frequency of $37 \mathrm{~Hz}$ which is derived from the resonance of train wheel and rail. Autocorrelation function of G1 and cross-correlation functions between G1 and the other three points G2 to G4 was calculated with NExT and plotted in Figure 21. The three correlation functions as well as the autocorrelation function of G1 are stacked in the $y$ axis based on the propagation distance from G1. By identifying the event points from the four curves in Figure 21, a straight line can be drawn while the slope of the line indicates the wave velocity of $684 \mathrm{~m} / \mathrm{s}$.
(2) Types of Vibration Waves in the Soil. Based on the results above, the vertical wave velocity in the soil $(684 \mathrm{~m} / \mathrm{s})$ is very close to the measured in situ compression wave velocity of soft clay. It can be inferred that compression wave is the dominant wave type in the vertical direction.

5.3. Propagation Velocities of Vibration Waves in the Underground Structure. The wave velocities in the metro station side wall were also analyzed by using the combined NExT and HHT method and were compared with the ones in the soil. Figure 22(a) plots the cross-correlation function between 


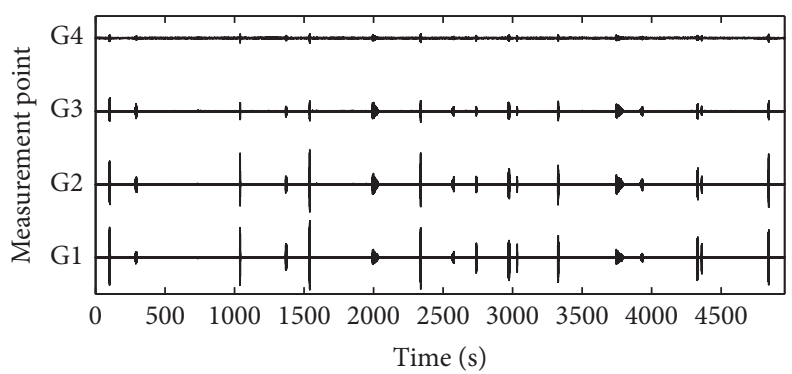

(a)

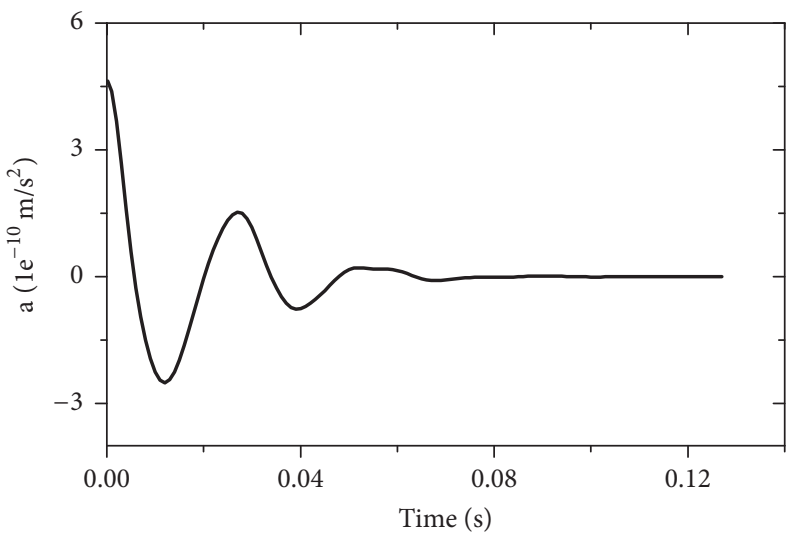

(b)

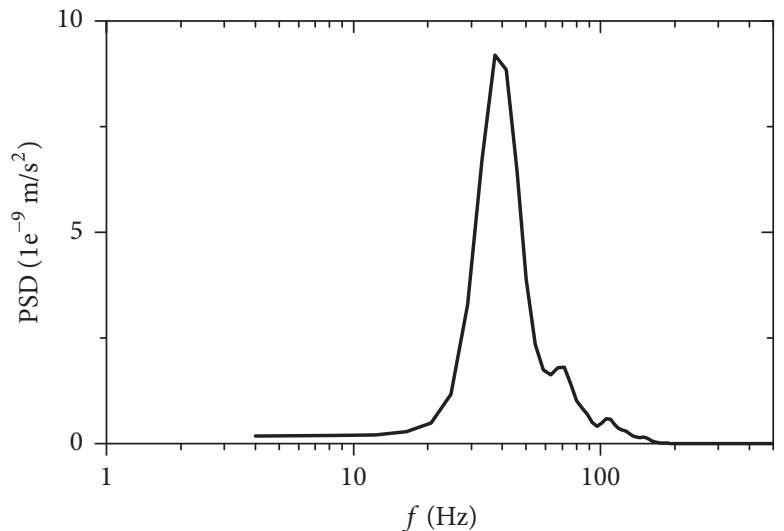

(c)

FIgURE 20: (a) The time history of the acceleration for measurement points G1 to G4 after 5000 seconds continuous acquisition, (b) autocorrelation function after the NExT processing for G1, and (c) PSD frequency spectrum of signal in (b).

W1 and W3. The PSD frequency spectrum of the crosscorrelation function in Figure 22(d) shows two peaks. After applying the decomposition based on HHT, two intrinsic mode functions (IMF1 and IMF2) corresponding to the two peaks can be obtained, as shown in Figures 22(b) and 22(c), respectively. The dominating frequency of IMF2 is consistent with the one for the soil (see Figure 20(c)).

The same procedure was applied to get IMF1 and IMF2 of the autocorrelation function of W1 and other two points W2-W3 on the wall of the metro station, the results plotted in Figures 23(a) and 23(b), respectively. By identifying the event points, two wave velocities can be determined as $2352 \mathrm{~m} / \mathrm{s}$ and
$3636 \mathrm{~m} / \mathrm{s}$. These two velocities are consistent with the shear wave velocity $\left(c_{s}\right)$ and the compression wave velocity $\left(c_{p}\right)$ of concrete, which can be determined by (6) as $2328 \mathrm{~m} / \mathrm{s}$ and $3800 \mathrm{~m} / \mathrm{s}$, respectively.

$$
\begin{aligned}
& c_{p}=\sqrt{\frac{\lambda+2 \mu}{\rho}}, \\
& c_{s}=\sqrt{\frac{\mu}{\rho}}
\end{aligned}
$$




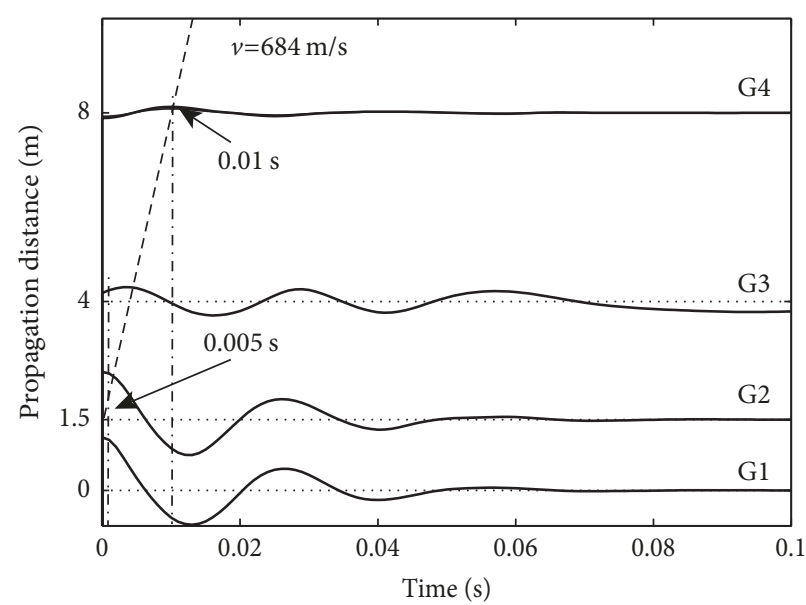

FIGURE 21: Autocorrelation function of G1 and cross-correlation functions between G1 and the other three points G2 to G4 in the soil and the determination of vertical wave velocity.

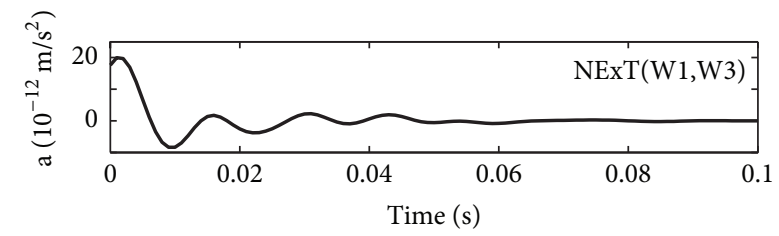

(a)

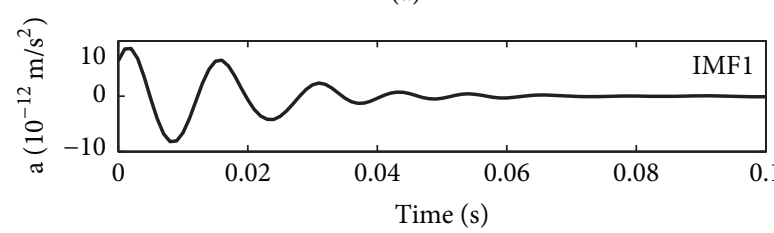

(b)
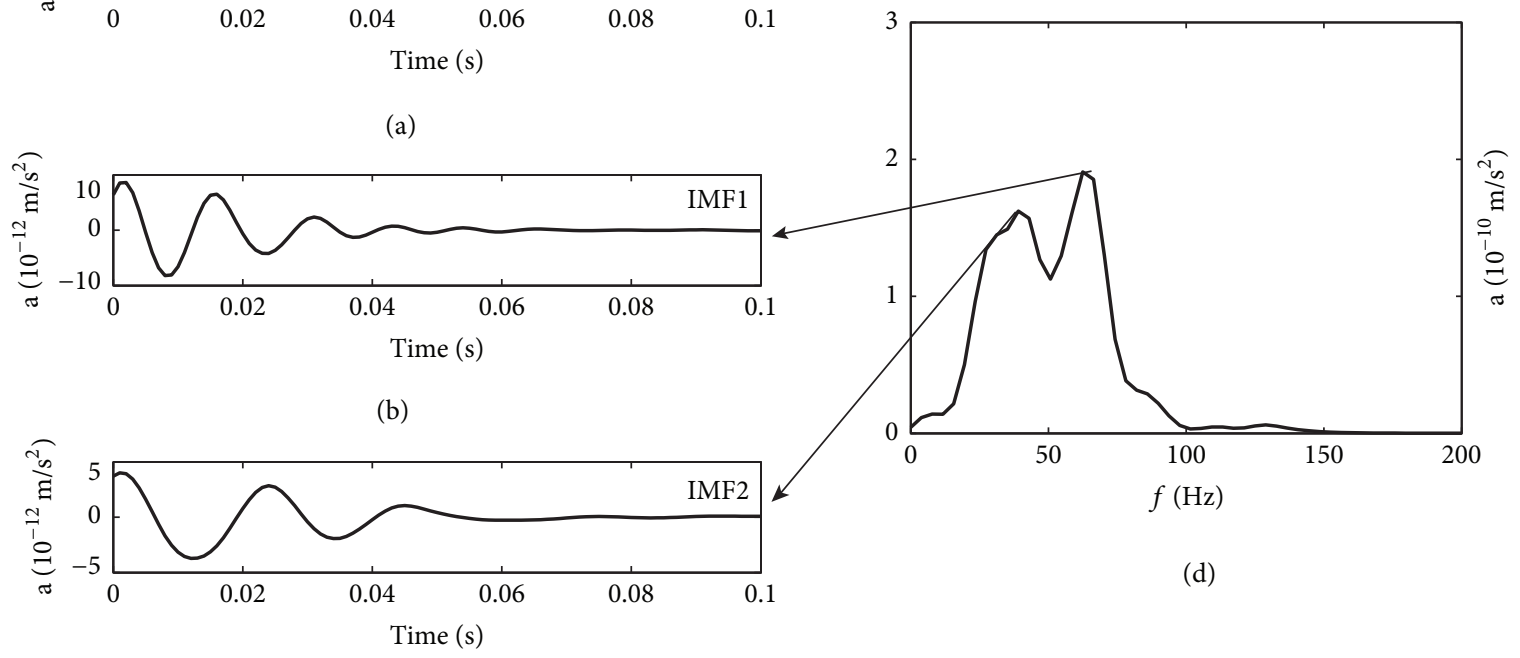

(c)

FIGURE 22: (a) Cross-correlation function between W1 and W3; (b) first intrinsic mode function (IMF1) based on HHT; (c) second intrinsic mode function (IMF2) based on HHT; (d) PSD frequency spectrum of the correlation function in (a) with the two peaks corresponding to the two intrinsic mode functions.

$$
\begin{aligned}
& \lambda=\frac{\nu E}{(1+\nu)(1-2 v)}, \\
& \mu=\frac{E}{2(1+\nu)},
\end{aligned}
$$

and their propagation speeds in the underground station can be obtained by combining NExT and HHT. Meanwhile, any structural performance deterioration will result in the body wave speed changes; this method thus can be used to monitor the service performance of underground structures.

where $E$ is the elastic modulus of concrete and equal to $3.25 e 10 \mathrm{~Pa}$; $v$ is Poission's ratio and equal to 0.2 ; the density $\rho$ is taken as $2500 \mathrm{~kg} / \mathrm{m}^{3}$.

From the analysis above, it is found that, under the excitation of train induced vibration, the body wave types

\section{Conclusions and Discussions}

To investigate the feasibility of using vibration characteristics for the health monitoring of underground structures, field vibration tests were carried out at the metro station underneath the high speed railway. The following conclusions are 


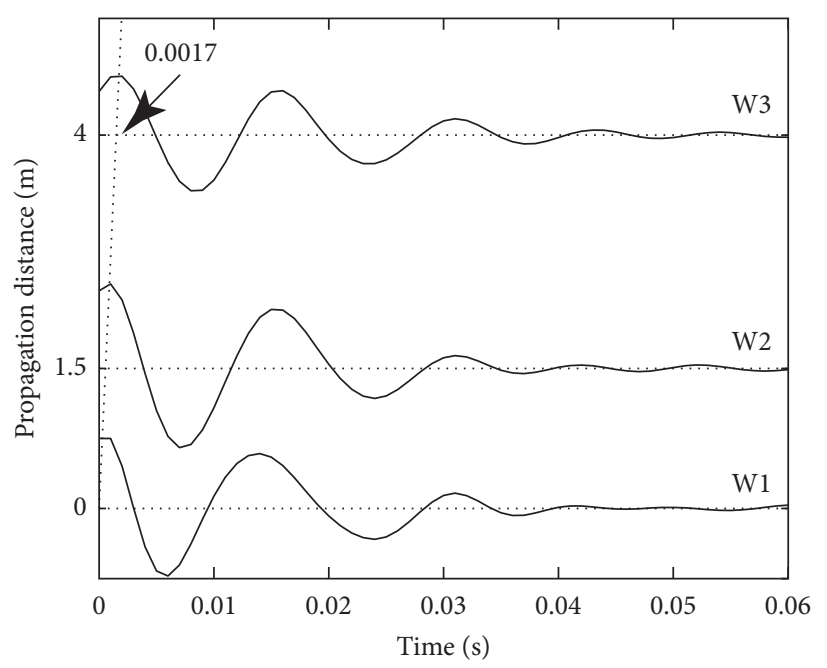

(a)

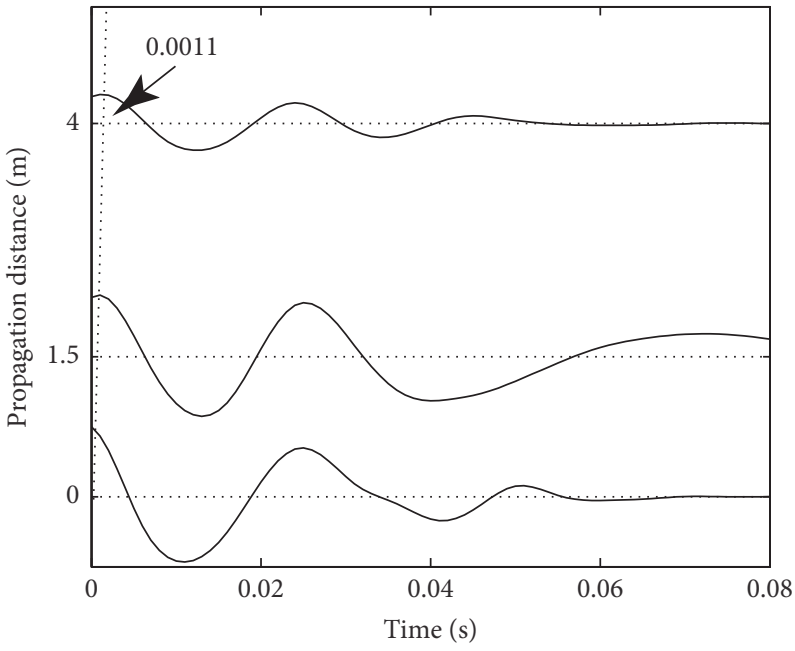

(b)

FIGURE 23: (a) IMF1 of the autocorrelation function of W1 and the cross-correlation functions between W1 and the other two points W2-W3 on the wall for the determination of vertical wave velocity and (b) the same plot for IMF2.

made based on the measured vibration characteristics of the underground structures and the surrounding soil.

(1) The attenuation characteristics of the vibration waves for the propagation in the underground structure and soil are subject to the stiffness of the underground structure. The attenuation index $m$ decreases as the effect of the structural stiffness increases.

(2) The results from the ambient test showed that the underground metro station and surrounding soil shared many resonance frequencies. And, together with the constraining and damping effects from the soil, the recognition and extraction of the frequency response characteristics for the structure only are very challenging.

(3) The train induced vibration is the common exciting source in the underground space. The metro station structure and soil show good transmission properties at the low frequency range below $10 \mathrm{~Hz}$ based on the transfer function and displacement analysis. And the interference of axis spectral and other characteristics of the train and rail system will make the recognition and extraction of frequency response characteristics difficult for the underground structures. However, the waveform and propagation velocities of vibration waves in underground structure and surrounding soil can be obtained by using the combined NExT and HHT method, and the vibration wave types in the structure and in the surrounding soil can also be determined and separated.

The following suggestions are given for the health monitoring in underground structures by using vibration characteristics.

(1) Because of the coupling between the underground structures and the surrounding soil, the recognition of the structure mode characteristics and the differentiation from the mode characteristics of soil becomes difficult. Therefore, the mode based method is more suitable for cases of large excavation monitoring, which will result in great change to the modes characteristics. The results also suggest that a wider frequency band is required for the underground structures monitoring than bridges or tall buildings and measurement points should be installed in both the structures and the soil.

(2) Attenuation index, natural frequency, and vibration wave velocity can all be used to evaluate the stiffness change for the underground structures. Compared with the attenuation index or natural frequency, wave velocity is easier to be recognized, is sensitive to the change of the structural stiffness, and requires limited number of sensors in the field. Based on the properties of the vibration characteristics studied in this work, the wave velocity based method is recommended for the health monitoring of underground structures.

\section{Data Availability}

All data related to this study can be provided upon sending email request to zhoubiao@tongji.edu.cn.

\section{Authors' Contributions}

Xiongyao Xie was the PI of this research project, while Biao Zhou and Fengshou Zhang were the major group members to execute the project. Biao Zhou was responsible for making the testing plan and collecting the data. Fengshou Zhang together with Biao Zhou finished the data analysis and paper writing.

\section{Conflicts of Interest}

The authors declare that there are no conflicts of interest regarding the publication of this paper. 


\section{Acknowledgments}

This research was initiated by Shanghai Shentong Metro Co., Ltd. Partial support was also received from the National Natural Science Foundation of China under Grants 51608379 and 51778476 and Shanghai Science and Technology Innovation Plan Funds under Grant 15DZ1203903. Those supports are greatly appreciated.

\section{References}

[1] S. Bhalla, Y. W. Yang, J. Zhao, and C. K. Soh, "Structural health monitoring of underground facilities-technological issues and challenges," Tunnelling and Underground Space Technology, vol. 20, no. 5, pp. 487-500, 2005.

[2] P. J. Bennett, Y. Kobayashi, K. Soga, and P. Wright, "Wireless sensor network for monitoring transport tunnels," Proceedings of the Institution of Civil Engineers: Geotechnical Engineering, vol. 163, no. 3, pp. 147-156, 2010.

[3] M. Bahrekazemi and A. Bodare, Train-induced ground vibration and its prediction [Ph.D. thesis], Royal Institute of Technology, Stockholm, Sweden, 2004.

[4] D. S. Kim and J. S. Lee, "Propagation and attenuation characteristics of various ground vibrations," Soil Dynamics and Earthquake Engineering, vol. 19, no. 2, pp. 115-126, 2000.

[5] E. P. Carden and P. Fanning, "Vibration based condition monitoring: a review," Structural Health and Monitoring, vol. 3 , no. 4, pp. 355-377, 2004.

[6] H. Li, J. Ou, X. Zhang, M. Pei, and N. Li, "Research and practice of health monitoring for long-span bridges in the mainland of China," Smart Structures and Systems, vol. 15, no. 3, pp. 555-576, 2015.

[7] Q. S. Li and J. Y, "Monitoring of, dynamic behavior of supertall buildings during typhoons," Structure and Infrastructure Engineering, vol. 12, no. 3, p. 23, 2005.

[8] F. Lorenzoni, F. Casarin, M. Caldon, K. Islami, and C. Modena, "Uncertainty quantification in structural health monitoring: Applications on cultural heritage buildings," Mechanical Systems and Signal Processing, vol. 66-67, pp. 268-281, 2016.

[9] C. Newton and R. Snieder, "Estimating intrinsic attenuation of a building using deconvolution interferometry and time reversal," Bulletin of the Seismological Society of America, vol. 102, no. 5, pp. 2200-2208, 2012.

[10] C. E. Ventura, W. D. Liam Finn, J.-F. Lord, and N. Fujita, "Dynamic characteristics of a base isolated building from ambient vibration measurements and low level earthquake shaking," Soil Dynamics and Earthquake Engineering, vol. 23, no. 4, pp. 313-322, 2003.

[11] N. Nakata and R. Snieder, "Monitoring a building using deconvolution interferometry. II: Ambient-vibration analysis," Bulletin of the Seismological Society of America, vol. 104, no. 1, pp. 204-213, 2014.

[12] S. M. J. Spence, E. Bernardini, Y. Guo, A. Kareem, and M. Gioffrè, "Natural frequency coalescing and amplitude dependent damping in the wind-excited response of tall buildings," Probabilistic Engineering Mechanics, vol. 35, pp. 108-117, 2014.

[13] Z. Zhang, K. Shankar, E. V. Morozov, and M. Tahtali, "Vibration-based delamination detection in composite beams through frequency changes," Journal of Vibration and Control, vol. 22, no. 2, pp. 496-512, 2016.
[14] M. Stache, M. Guettler, and S. Marburg, "A precise nondestructive damage identification technique of long and slender structures based on modal data," Journal of Sound and Vibration, vol. 365, pp. 89-101, 2016.

[15] H. Hothu, A. Mita, J. P. Lynch, C. Yun, and K. Wang, "Assessment and evaluation of damage detection method based on modal frequency changes," in Sensors and Smart Structures Technologies for Civil, Mechanical, and Aerospace Systems, p. 86923M, San Diego, Calif, USA.

[16] D. Bindi, B. Petrovic, S. Karapetrou et al., "Seismic response of an 8-story RC-building from ambient vibration analysis," Bulletin of Earthquake Engineering, vol. 13, no. 7, pp. 2095-2120, 2015.

[17] T. H. Ooijevaar, L. L. Warnet, R. Loendersloot, R. Akkerman, and T. Tinga, "Impact damage identification in composite skin-stiffener structures based on modal curvatures," Structural Control \& Health Monitoring, vol. 23, no. 2, pp. 198-217, 2016.

[18] D. Dessi and G. Camerlengo, "Damage identification techniques via modal curvature analysis: overview and comparison," Mechanical Systems and Signal Processing, vol. 52-53, pp. 181205, 2015.

[19] F. Musafere, A. Sadhu, and K. Liu, "Towards damage detection using blind source separation integrated with time-varying auto-regressive modeling," Smart Materials and Structures, vol. 25, no. 1, Article ID 015013, 2015.

[20] J. A. Goulet, C. Michel, and A. D. Kiureghian, "Data-driven post-earthquake rapid structural safety assessment," Earthquake Engineering \& Structural Dynamics, vol. 44, no. 4, pp. 549-562, 2015.

[21] J. P. Amezquita-Sanchez and H. Adeli, "Signal processing techniques for vibration-based health monitoring of smart structures," Archives of Computational Methods in Engineerin: State-of-the-Art Reviews, vol. 23, no. 1, pp. 1-15, 2016.

[22] B. Zhou, X. Y. Xie, Y. B. Yang, and J. C. Jiang, "A novel vibrationbased structure health monitoring approach for the shallow buried tunnel," CMES-Comp Model Eng, vol. 86, no. 4, pp. 321348, 2012.

[23] X. Y. Xie and Y. S. Li, "A structural health assessment method for shield tunnels based on torsional wave speed," Science China Technological Sciences, vol. 57, no. 6, pp. 1109-1120, 2014.

[24] Y. Zhang, J. Lian, and F. Liu, "An improved filtering method based on EEMD and wavelet-threshold for modal parameter identification of hydraulic structure," Mechanical Systems and Signal Processing, vol. 68-69, pp. 316-329, 2016.

[25] F. Butt and P. Omenzetter, "Seismic response trends evaluation and finite element model calibration of an instrumented $\mathrm{RC}$ building considering soil-structure interaction and nonstructural components," Engineering Structures, vol. 65, pp. 111123, 2014.

[26] A. Galvagni and P. Cawley, "The reflection of guided waves from simple supports in pipes," The Journal of the Acoustical Society of America, vol. 129, no. 4, pp. 1869-1880, 2011.

[27] A. B. Thien, H. C. Chiamori, J. T. Ching, J. R. Wait, and G. Park, "The use of macro-fibre composites for pipeline structural health assessment," Structural Control and Health Monitoring, vol. 15, no. 1, pp. 43-63, 2008.

[28] B. K. Raghuprasad, N. Lakshmanan, N. Gopalakrishnan, K. Sathishkumar, and R. Sreekala, "Damage identification of beam-like structures with contiguous and distributed damage," Structural Control and Health Monitoring, vol. 20, no. 4, pp. 496-519, 2013. 
[29] M. Heckl, G. Hauck, and R. Wettschureck, "Structure-borne sound and vibration from rail traffic," Journal of Sound and Vibration, vol. 193, no. 1, pp. 175-184, 1996.

[30] Y.-B. Yang and H.-H. Hung, "A 2.5D finite/infinite element approach for modelling visco-elastic bodies subjected to moving loads," International Journal for Numerical Methods in Engineering, vol. 51, no. 11, pp. 1317-1336, 2001.

[31] J. A. Forrest and H. E. M. Hunt, "Ground vibration generated by trains in underground tunnels," Journal of Sound and Vibration, vol. 294, no. 4, pp. 706-736, 2006.

[32] G. Degrande, M. Schevenels, P. Chatterjee et al., "Vibrations due to a test train at variable speeds in a deep bored tunnel embedded in London clay," Journal of Sound and Vibration, vol. 293, no. 3-5, pp. 626-644, 2006.

[33] ASTM D1586-11:Standard Test Method for Standard Penetration Test (SPT) and Split-Barrel Sampling of Soils, https://compass.astm.org/EDIT/html_annot.cgi?D1586+11.

[34] J. A. Cao, "Correlation between seismic velocity and blow count and depth of standard penetration test for soft soil in Shanghai," Chinese Journal of Geotechnical Engineering, vol. 1, pp. 68-75, 1985.

[35] ISO 5348:1987 Mechanical vibration and shock - mechanical mounting of accelerometers, https://www.iso.org/standard/ 25068.html.

[36] T. Hashiba and R. V. Whitman, "Soil-Structure Interaction during Earthquakes," Journal of the Soil Mechanics and Foundations Division, vol. 94, no. 2, pp. 951-979, 1968.

[37] J. T. Nelson, H. J. Saurenman, and G. P. Wilson, State-of-theArt Review: Prediction and Control of Ground borne Noise and Vibration from Rail Transit, U.S. Department of Transportation Report DOT-TSC-UMTA-83-3, 1983.

[38] N. E. Huang, Z. Shen, S. R. Long et al., "The empirical mode decomposition and the Hilbert spectrum for nonlinear and non-stationary time series analysis," Proceedings of The Royal Society A, vol. 454, pp. 903-995, 1998.

[39] G. H. James and T. C. Carne, "The natural excitation technique (NExT) for modal parameter extraction from ambient operating structure," The international Journal of Analytical and Experimental Modal Analysis, vol. 10, no. 4, pp. 260-277, 1995.

[40] M. O. Al-Hunaidi, "Insights on the SASW nondestructive testing method," Canadian Journal of Civil Engineering, vol. 20, no. 6, pp. 940-950, 1993. 


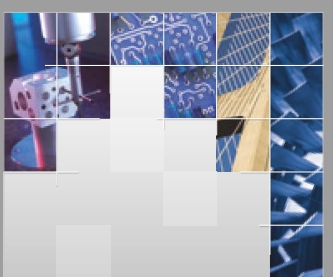

\section{Enfincering}
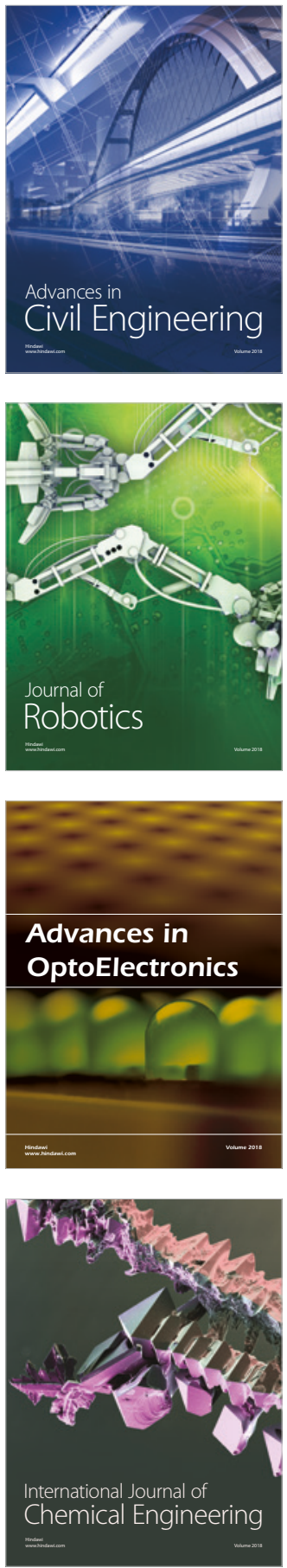

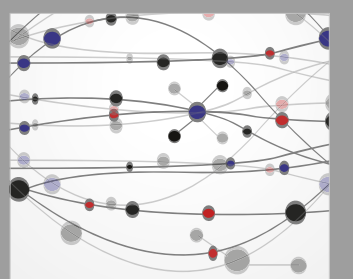

\section{Rotating \\ Machinery}

The Scientific World Journal

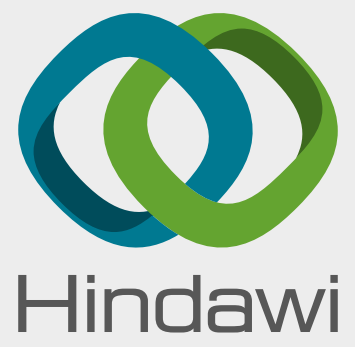

Submit your manuscripts at

www.hindawi.com
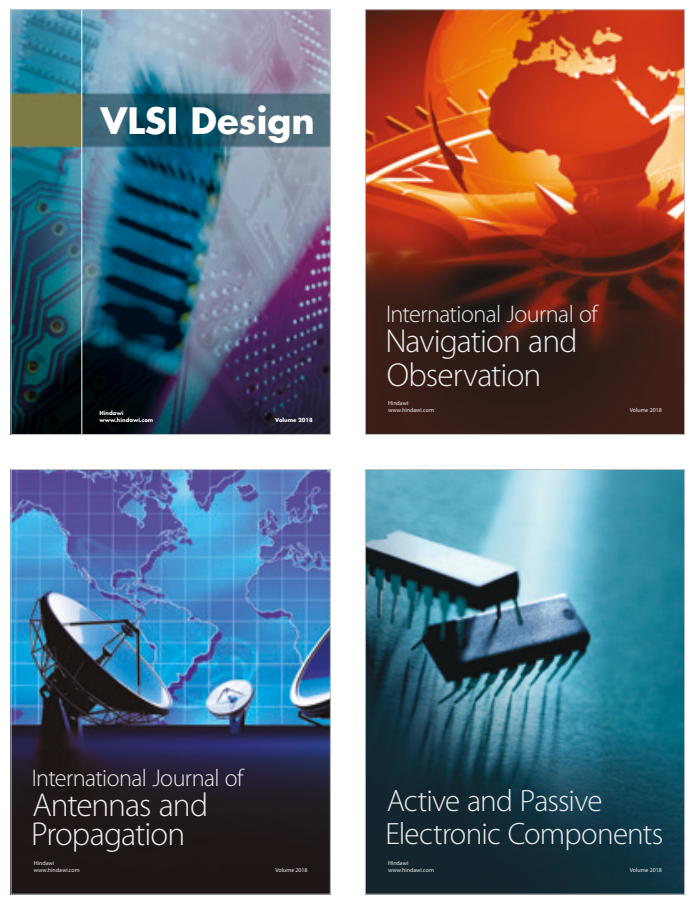
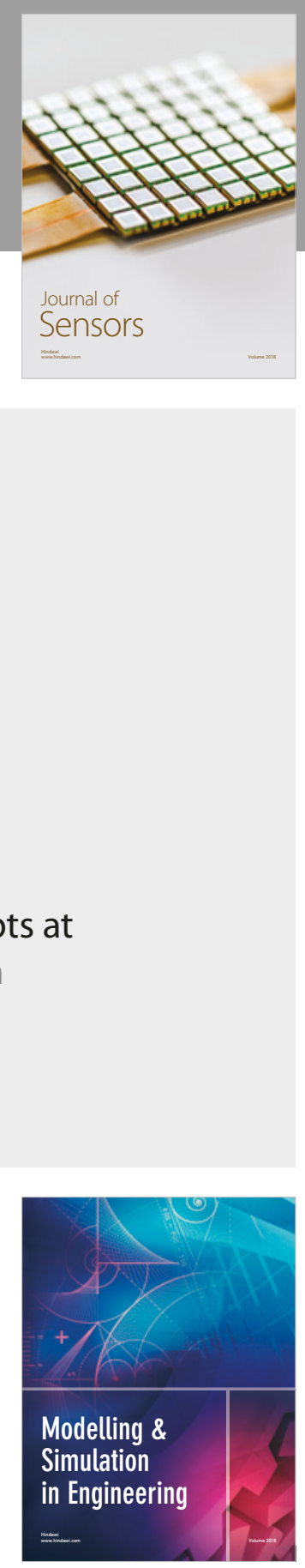

\section{Advances \\ Multimedia}
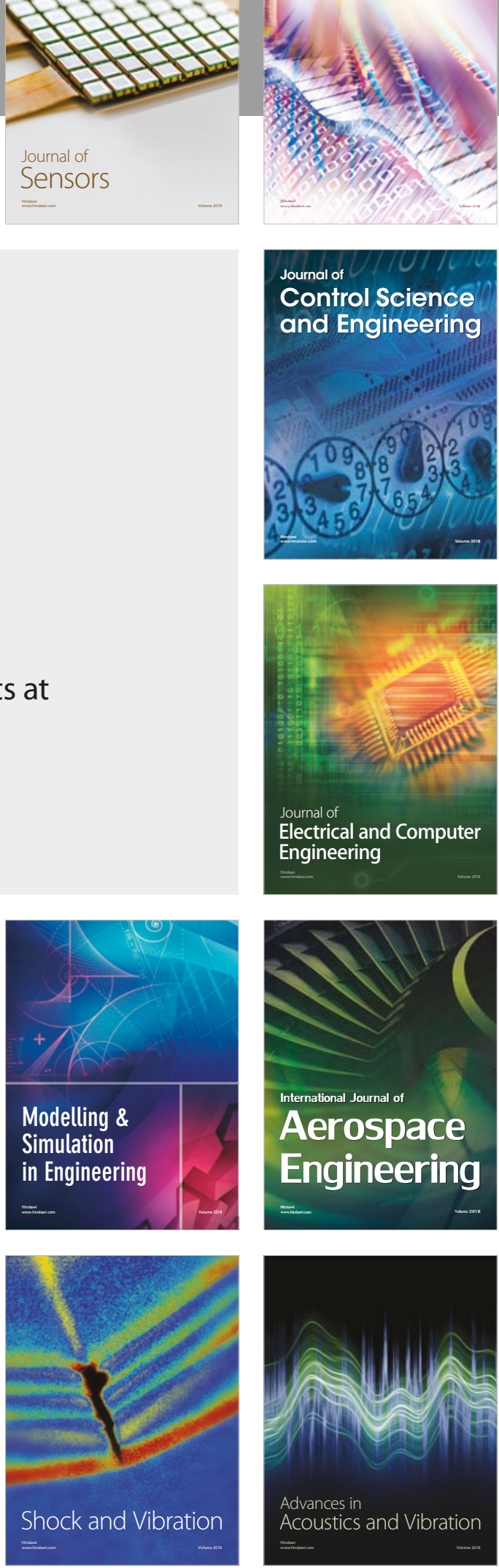